\title{
Geomorfologia e Tectônica da Formação Barreiras no Estado da Paraíba
}

\author{
Max Furrier'1 (mfurrier@usp.br), Magno Erasto de Araúio², Leonardo Figueiredo de Meneses ${ }^{3}$ \\ 'Pós-Graduação em Geografia Física - Departamento de Geografia - FFLCH - USP \\ Av. Prof. Lineu Prestes 338, CEP 05508-900, São Paulo, SP, BRA \\ ${ }^{2}$ Departamento de Geociências - CCEN - UFPB, João Pessoa, PB, BRA \\ ${ }^{3}$ Pós-Graduação em Engenharia Urbana - CT - UFPB, João Pessoa, PB, BRA
}

Recebido em 27 de janeiro de 2006; aceito em 27 de junho de 2006

Palavras-chave: Tabuleiros Litorâneos, Formação Barreiras, superfícies geomorfológicas.

\section{RESUMO}

Este trabalho aborda alguns aspectos estruturais e morfológicos dos Tabuleiros Litorâneos no Estado da Paraíba. Esses tabuleiros desenvolveram-se, predominantemente, sobre os sedimentos areno-argilosos e mal consolidados da Formação Barreiras. Essa formação repousa de forma discordante, de oeste para leste, sobre o embasamento cristalino e sobre os sedimentos do Grupo Paraíba, depositados na Bacia Sedimentar Marginal Pernambuco-Paraíba. A partir de levantamentos cartográficos, aerofotogramétricos, interpretações de imagens orbitais, observações em campo, análises de perfis topográficos e de poços tubulares e, da integração e interpretação das informações obtidas, pode-se concluir que as reativações tectônicas pós-cretácicas constituem o fator mais importante na configuração morfológica da área de estudo. Essas reativações foram responsáveis por soerguimentos distintos e basculamentos de superfícies geomorfológicas, além de criar inúmeros e extensos falhamentos que dinamizaram entalhes e orientaram dissecações, definindo a compartimentação e a configuração atual dos Tabuleiros Litorâneos.

Keywords: Coastal Tablelands, Barreiras Formation, geomorphological surface.

\section{ABSTRACT}

This work investigates structural and morphological aspects of the Coastal Tablelands in the State of Paraíba. These tablelands were developed predominantly on clayey-sandy sediments of the Barreiras Formation. This formation irregularly overlies, from west to east, the crystalline basement and sediments of the Paraíba Group, deposited in the PernambucoParaíba marginal sedimentary basin. Integration and interpretation of information from cartographic, aerophotogrammetric surveys, satellite images, field work, topographic profiles, and water-well analyses provide ample evidence that tectonic reactivation of post-Cretaceous faults constitutes the most important factor controlling the morphological configuration of the study area. Reactivation of these faults not only uplifted and tilted geomorphological surfaces, but also accelerated downcutting, controlled dissection, and defined the compartmentalization and current configuration of the Coastal Tablelands. 


\section{INTRODUÇÃO}

O presente trabalho tem como propósito apresentar uma síntese sobre os diversos aspectos estruturais e morfológicos da Formação Barreiras no Estado da Paraíba observados, sobretudo, em análises de cartas topográficas e geológicas, fotografias aéreas, imagens orbitais, sondagens por poços tubulares e levantamentos de campo.

Mais precisamente, a área de estudo abrange um polígono aproximadamente retangular de direção norte-sul, tendo como limite norte a divisa entre a Paraíba e o Rio Grande do Norte e, ao sul, o rio Goiânia, fronteira natural entre os Estados da Paraíba e Pernambuco. Na direção leste-oeste, a Formação Barreiras, segundo o mapa geológico do Estado da Paraíba (Brasil, 2002), alcança extensões variáveis, entre 30 a $50 \mathrm{~km}$.

No Estado da Paraíba, essa unidade litoestratigráfica repousa de forma discordante, respectivamente de oeste para leste, sobre o embasamento cristalino pré-cambriano e sobre os sedimentos do Grupo Paraíba depositados na Bacia Marginal Pernambuco-Paraíba.

\section{CARACTERIZAČ̃̃ GEOLÓGICA DA ÁREA DE EŚTUDO}

Na região adjacente à área de estudo, o embasamento cristalino é constituído por três terrenos distintos denominados, de norte para sul, de Terreno Alto Pajeú, Terreno Alto Moxotó e Terreno Rio Capibaribe (Brasil, 2002). Esses terrenos são delimitados por grandes lineamentos e zonas de cisalhamento com direção predominantemente leste-oeste. Provavelmente, essas estruturas estendem-se sob a Formação Barreiras e sob os sedimentos do Grupo Paraíba da Bacia Pernambuco-Paraíba, adentrando pela margem continental adjacente.

Mabesoone e Alheiros (1988), a partir de informações sobre linhas estruturais, natureza litológica e interpretação geofísica propuseram subdividir a Bacia PernambucoParaíba em cinco sub-bacias. Alheiros, Lima Filho e Ferreira (1989) e Mabesoone e Alheiros (1991) excluíram da Bacia Pernambuco-Paraíba, respectivamente, a subbacia Cabo (extremo sul) e a sub-bacia Natal e a porção norte da sub-bacia Canguaretama, porque estas apresentam características estratigráficas, geocronológicas e estruturais distintas das demais sub-bacias. A porção sul da sub-bacia Canguaretama foi denominada de sub-bacia Miriri (Mabesoone e Alheiros, op cit.). Portanto, restam apenas para a Bacia Pernambuco-Paraíba as subbacias Miriri, Alhandra e Olinda. O atual limite da Bacia Pernambuco-Paraíba se faz pelo Lineamento Pernambuco, ao sul, e pela falha de Pirpirituba ou Mamanguape, ao norte (Figura 1).
A unidade litoestratigráfica basal da Bacia Sedimentar Pernambuco-Paraíba é denominada de Formação Beberibe. Essa unidade é representada por um espesso pacote de arenitos com granulação variável e com espessuras médias de 230 a 280 m, e máxima de 360 m (Leal e Sá, 1998).

Superposta à Formação Beberibe, repousa de forma concordante a Formação Gramame. Essa unidade carbonática, de ambiente marinho raso, possui espessura média inferior a $55 \mathrm{~m}$, dos quais mais de dois terços são representados por calcários argilosos cinzentos (Leal e Sá, 1998). Segundo Almeida (2000), a espessura máxima encontrada para essa formação é de $70 \mathrm{~m}$.

A Formação Maria Farinha representa a continuação da sequiência calcária da Formação Gramame, sendo diferenciada apenas pelo seu conteúdo fossilífero, que é considerada de idade paleocênica-eocênica inferior (Mabesoone, 1994). Apresenta espessura máxima de $35 \mathrm{~m}$, provavelmente erodida em parte pela exposição subaérea anterior à deposição dos sedimentos continentais da Formação Barreiras (Leal e Sá, 1998).

Recobrindo de forma discordante o embasamento cristalino pré-cambriano e as rochas sedimentares do Grupo Paraíba da Bacia Sedimentar Pernambuco-Paraíba, encontram-se os sedimentos areno-argilosos mal consolidados da Formação Barreiras (Figura 2).

Os sedimentos da Formação Barreiras provêm basicamente dos produtos resultantes da ação do intemperismo sobre o embasamento cristalino, localizado mais para o interior do continente. No Estado da Paraíba, este embasamento é composto pelas rochas cristalinas do Planalto da Borborema. Gopinath, Costa e Júnior (1993) em análises sedimentológicas realizadas na Formação Barreiras, no Estado da Paraíba, constataram que as fontes dos sedimentos seriam granitos, gnaisses e xistos, que são litologias predominantes no Planalto da Borborema.

Segundo Alheiros et al. (1988), a deposição dos sedimentos da Formação Barreiras se deu através de sistemas fluviais entrelaçados desenvolvidos sobre leques aluviais. A fácies de sistemas fluviais entrelaçados apresenta depósitos de granulometria variada com cascalhos e areias grossas a finas, de coloração creme amarelado, com intercalações de microclastos de argila síltica, indicativo de ambientes de sedimentação calmo como, por exemplo, de planície aluvial. A fácies de leques é constituída por conglomerados polimíticos de coloração creme-avermelhada, com seixos e grânulos subangulosos de quartzo e blocos de argila retrabalhada, em corpos tabulares e lenticulares de até um metro de espessura, intercalados com camada síltico-argilosa menos espessa.

Para Alheiros et al. (1988), a deposição dos sedimentos da Formação Barreiras representa a evolução de um sistema flu- 


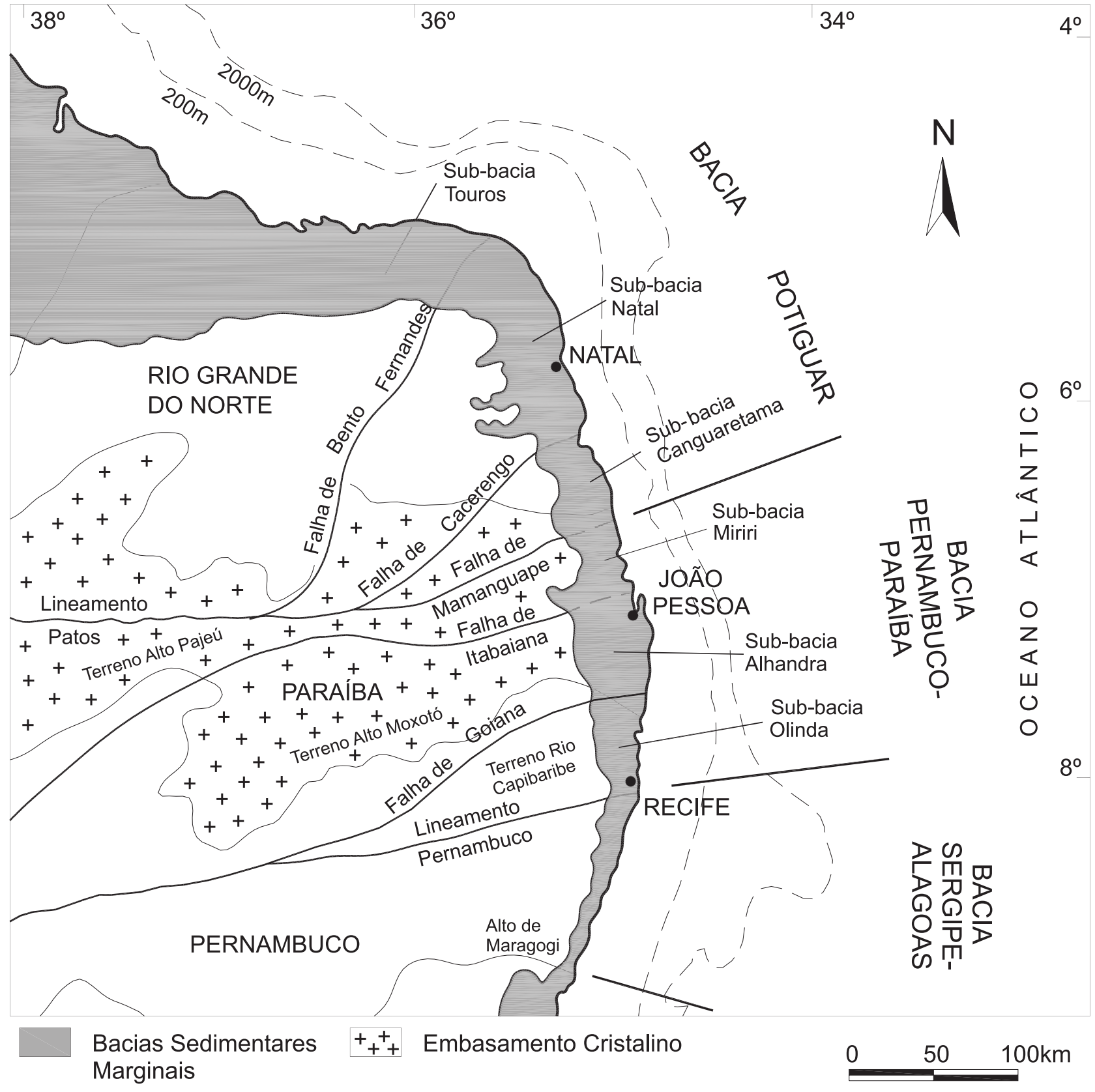

Figura 1. Sub-bacias Miriri, Alhandra e Olinda que compõem a Bacia Pernambuco-Paraíba (modificado de Barbosa, 2004). 


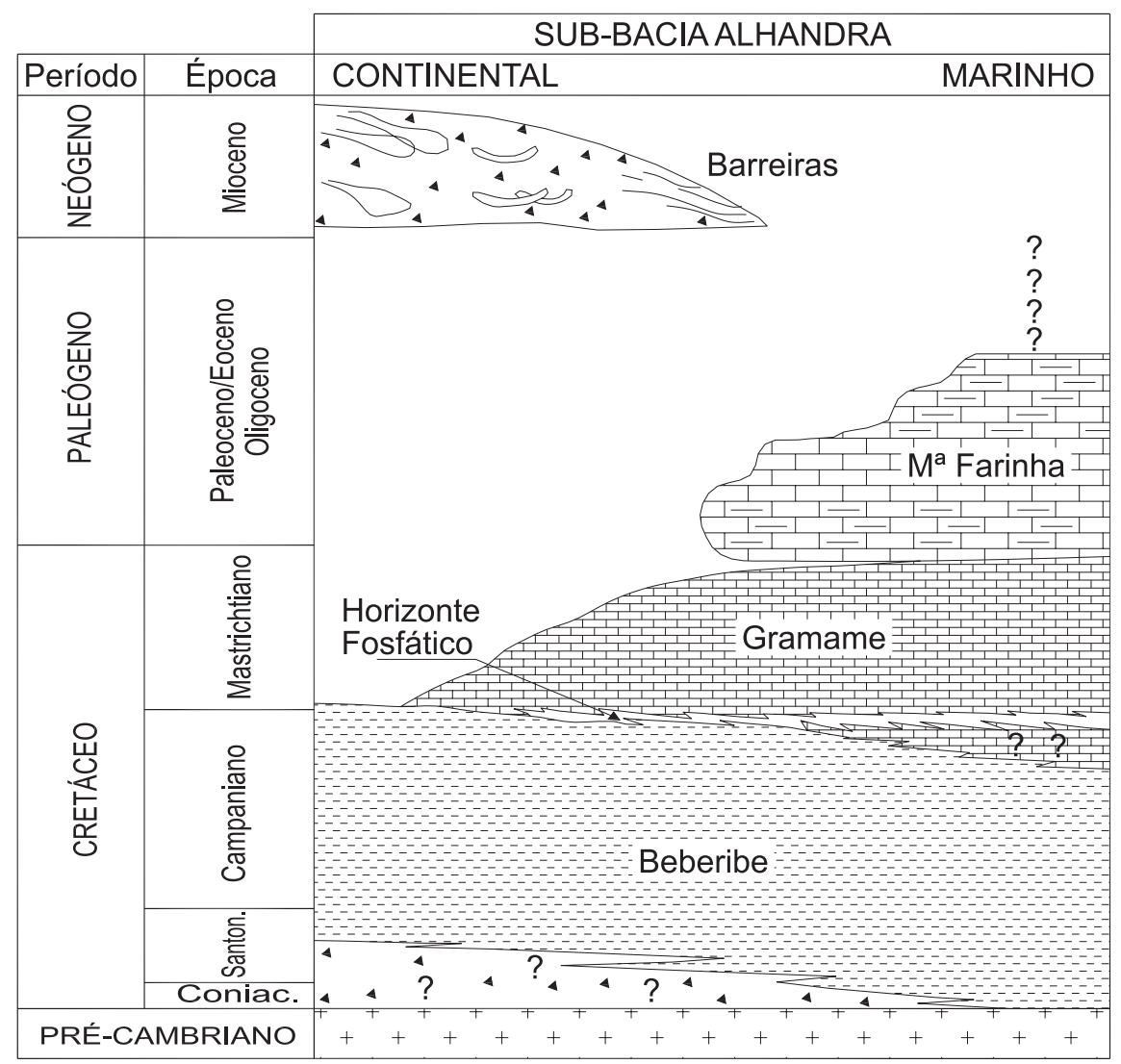

Figura 2. Coluna estratigráfica esquemática da Bacia Pernambuco-Paraíba no trecho da sub-bacia Alhandra (modificada de Barbosa et al., 2004).

vial desenvolvido em fortes gradientes e sob clima predominantemente árido e sujeito a oscilações.

Arai (2005) questionou a origem continental da Formação Barreiras tradicionalmente apregoada e admitiu origem predominantemente marinha para a mesma. Através de estudos palinológicos, Arai et al. (1988) posicionaram a parte inferior dessa formação no Mioceno inferior a médio.

A espessura da Formação Barreiras do Estado da Paraíba é bastante variável, atingindo espessuras máximas entre 70 e 80 m (Leal e Sá, 1998). No final do ciclo deposicional, a espessura deste pacote sedimentar era, provavelmente, muito superior à atual, pois a região foi dominada por processos denudacionais desde o Plioceno. As diferentes espessuras ora verificadas estão sendo explicadas recentemente por estudos de tectônica regional cenozóica, originadas por reativações de antigas falhas no embasamento cristalino do Proterozóico (Brito Neves et al., 2004).

Em função das semelhanças litológicas com a Formação Beberibe, a identificação da Formação Barreiras em campo e, conseqüentemente, o seu mapeamento, é extremamente difícil, sobretudo, na ausência da Formação Gramame (inter- mediária). Essa formação funciona como uma camada guia entre as Formações Beberibe e Barreiras. Geralmente, a Formação Gramame é encontrada somente até $20 \mathrm{~km}$ continente adentro, havendo, portanto, a partir desse ponto, grande dificuldade em diferenciar as Formações Barreiras e Beberibe somente por observações de campo, principalmente quando submetidas ao intenso intemperismo.

\section{ASPECTOS TECTÔNICOS E ESTRUTURAIS REGIONAIS}

Asmus (1975) interpretou a Bacia Pernambuco-Paraíba como resultado da fase final da evolução tectono-sedimentar das bacias marginais, caracterizada pela subsidência continuada da margem continental, resultando no espessamento vertical e avanço progradacional dos sedimentos. Rand (1976), utilizando métodos geofísicos, caracterizou-a como uma rampa de blocos falhados (escalonados) de gradiente muito suave, inclinada para leste.

Brito Neves et al. (2004) admitiram a existência de um sistema tafrogênico a leste do meridiano $36^{\circ} \mathrm{W}$, no Estado 
da Paraíba, resultante principalmente da reativação tectônica de componente distencional ao longo de antigas zonas de cisalhamento de direção E-W a ENE-WSW do embasamento proterozóico. Esta tectônica distencional seria posterior ao arqueamento pós-cretáceo.

Mais recentemente, pesquisas apontam que eventos tectônicos cenozóicos têm uma importância determinante na configuração do relevo atual. Esses eventos tectônicos foram ignorados no passado, mas vêm sendo enfatizados em estudos recentes. Trabalhos de Bezerra et al. (1998 e 2001), Bezerra e Vita Finzi (2000), Barreto et al. (2002) e Brito Neves et al. (2004) vêm mostrando a existência de movimentação tectônica, não somente extensionais, mas também gravitacionais, durante a Era Cenozóica, na costa do Nordeste brasileiro e retaguarda.

A identificação de processos rúpteis pós-cretáceo torna necessária uma revisão da geomorfologia dos Tabuleiros Litorâneos, principalmente com apoio de métodos geofísicos (Brito Neves et al., 2004).

Análises de poços tubulares perfurados na Bacia Pernambuco-Paraíba, na área de estudo, foram realizados por Araújo (1993), Leal e Sá (1998) e Barbosa (2004). Em todos os trabalhos, constatou-se uma grande variação nas cotas dos patamares do calcário da Formação Gramame, sugerindo a existência de falhas com consideráveis rejeitos, que podem afetar os tabuleiros superpostos.

A compartimentação dos Tabuleiros Litorâneos em distintos patamares topográficos já havia sido constatada nos tabuleiros do Estado de Sergipe por Ponte (1969) e Leite (1973). Estes pesquisadores observaram que a superfície dos tabuleiros apresentava-se quebrada por bruscos desníveis, delimitando patamares paralelos, sugestivos de reativação de falhamentos.

\section{ASPECTOS ESTRUTURAIS E GEOMORFOLÓGICOS DA ÁREA DE ESTUDO}

A partir das imagens Shuttle Radar Topographic Mission (SRTM) foi possível distinguir dois padrões de dissecação sobre os Tabuleiros Litorâneos no Estado da Paraíba. Esses padrões são delimitados pelo vale do rio Gramame (Figura 3a). Ao norte deste vale, predominam tabuleiros com grandes e bem definidas superfícies aplainadas, entrecortadas por vales fluviais aproximadamente perpendiculares a linha de costa. Quase sempre, é possível visualizar facilmente o limite dos topos dos tabuleiros com as respectivas vertentes.

Ao norte do rio Gramame, o relevo caracteriza-se por uma rede de drenagem de densidade muito inferior a da porção sul e com altitudes geralmente menores. Observase, principalmente nos afluentes do médio e baixo curso do rio Miriri, um padrão de drenagem extremamente influenciado pelo tectonismo (falhamento), pois os mesmos apresentam-se perpendiculares em ambas as margens ao curso principal segundo a direção NNW-SSE (Figura 3a). Esse padrão diferencia-se dos demais cursos que obedecem à inclinação regional dos tabuleiros que é de oeste para leste. O entalhamento fluvial médio desses afluentes atinge, em alguns pontos, profundidades superiores a $100 \mathrm{~m}$, superando os entalhes médios dos demais cursos da região.

Verifica-se que, diferentemente do compartimento localizado ao sul do rio Gramame, os rios do compartimento ao norte não exumam com a mesma intensidade as formações sedimentares do Grupo Paraíba depositadas na Bacia Pernambuco-Paraíba. Ocorrem apenas alguns pequenos afloramentos de calcário da Formação Gramame nos vales dos rios Miriri, Soé e Paraíba.

A partir de análises de cartas topográficas, ao longo dos Tabuleiros Litorâneos do compartimento norte, constata-se um comportamento semelhante a um teclado de piano, com setores soerguidos e rebaixados alternadamente, separados pelos principais rios perpendicularmente à linha de costa (Figura 3b). No sentido norte-sul, os tabuleiros localizados ao norte do rio Camaratuba exibem altitudes máximas entre 59 a $82 \mathrm{~m}$. Os tabuleiros localizados entre os rios Camaratuba e Mamanguape apresentam altitudes maiores que as adjacências, tanto ao norte como ao sul. Esse tabuleiro possui altitudes máximas variando entre 85 e 153 m, enquanto que no setor entre os rios Mamanguape e Miriri as altitudes são rebaixadas e variam entre 62 e $88 \mathrm{~m}$. O trecho dos tabuleiros localizados imediatamente ao sul do rio Miriri apresenta cotas altimétricas mais elevadas de todo o compartimento norte, variando entre 122 a $177 \mathrm{~m}$. Os tabuleiros da margem norte do rio Paraíba, até o vale do rio Jacuípe, apresentam cotas altimétricas máximas variando entre 79 e $97 \mathrm{~m}$. Os trechos localizados na margem sul do rio Paraíba, até o vale do rio Gramame (trecho que inclui o sítio urbano de João Pessoa), apresentam cotas altimétricas máximas variando entre 49 a $77 \mathrm{~m}$, e representam as partes mais rebaixadas de toda a área de estudo (Figuras 3a e 3b).

Essas variações altimétricas dos interflúvios, entre os principais rios perpendiculares à linha de costa, verificadas em cartas topográficas e corroboradas pela análise da imagem SRTM e do mapa geológico do Estado da Paraíba (Brasil, 2002), indicam existência de um forte controle estrutural na compartimentação dessas unidades de relevo. Portanto, essas considerações evidenciam a existência de setores de relevo soerguidos ou rebaixados, em função da tectônica regional, como se fosse um teclado de piano.

O compartimento de relevo localizado ao sul do vale do rio Gramame apresenta acentuadas diferenças em relação ao compartimento ao norte desse mesmo rio. As cotas altimétricas máximas ultrapassam 200 m e o ponto culminan- 


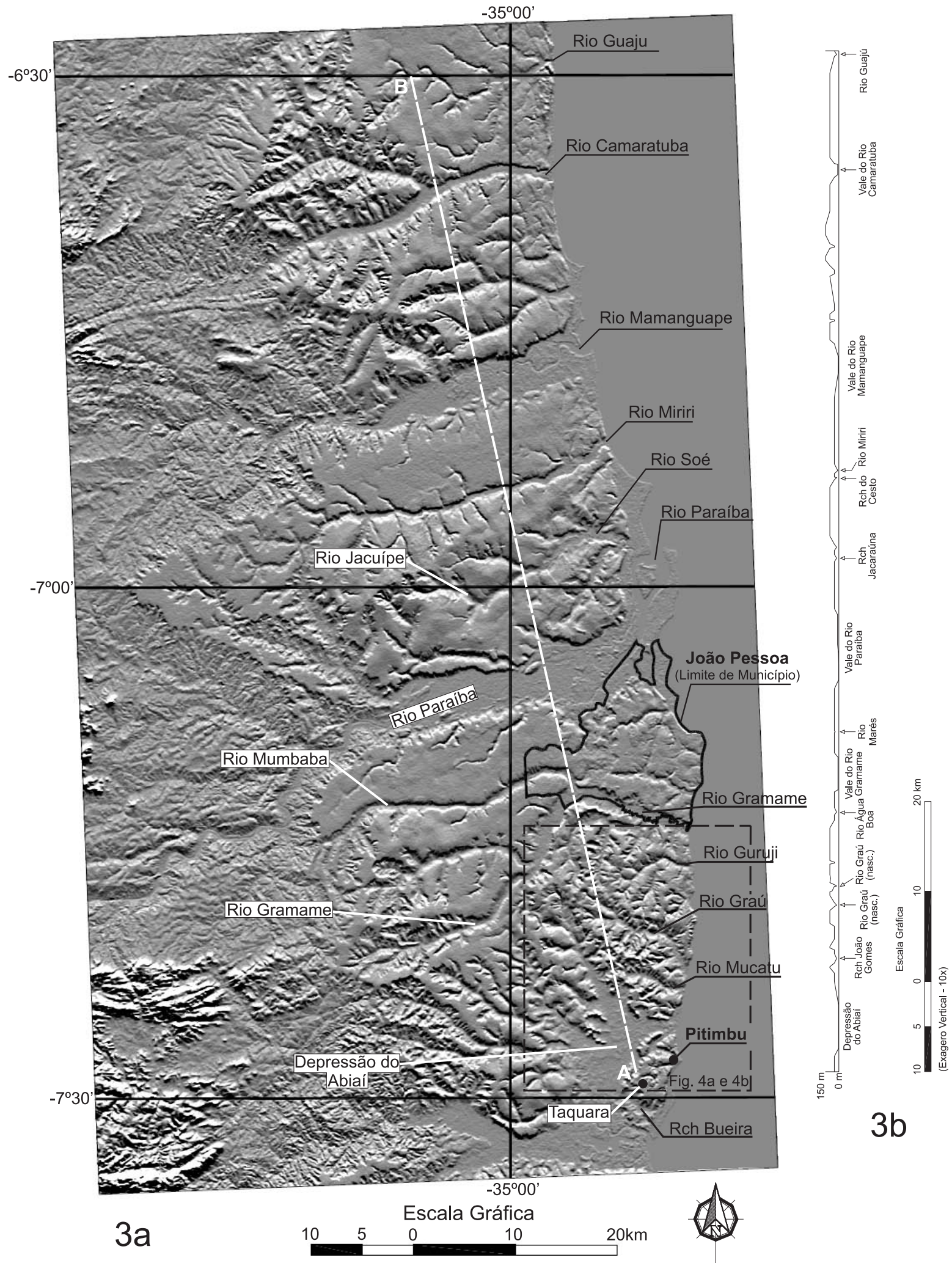

Figura 3. Imagem Shutle Radar Topographic Mission (SRTM) da faixa oriental do Estado da Paraíba e perfil topográfico NNW-SSE dos Tabuleiros Litorâneos. 
te da área de estudo apresenta cota de $213 \mathrm{~m}$. A rede de drenagem desse compartimento apresenta densidade superior e o entalhamento dos vales fluviais é mais profundo em relação ao compartimento norte. Esses entalhamentos mais profundos promovem a exumação de rochas sotopostas da Bacia Pernambuco-Paraíba, gerando vastos anfiteatros encaixados, com vertentes complexas de terraços estruturais em função das diferenças litológicas.

Semelhantemente ao compartimento a norte do vale do rio Gramame, o do sul também apresenta porções de relevo soerguidas e rebaixadas e, às vezes, até basculadas. A faixa entre os vales dos rios Guruji e Mucatu apresenta-se altimetricamente mais elevada que nas áreas adjacentes, ao norte, ao sul e ao oeste (Figuras 4a e 4b).

Observando o traçado do rio Gramame, percebem-se mudanças bruscas na direção da calha principal, bem como assimetria acentuada entre os afluentes da margem esquerda e direita do seu baixo curso. Essa mudança brusca de direção é bem evidenciada na imagem SRTM (Figura 3a) onde se percebe um nítido desvio do rio em consequiência de um provável soerguimento da porção leste. Esse provável soerguimento é corroborado pela existência de calcários da Formação Gramame aflorantes na margem direita do rio homônimo, nas imediações da confluência com o rio Mumbaba. Na margem esquerda desse rio, nas imediações dessa mesma confluência, esses calcários são atingidos somente através de poços tubulares a cerca de $20 \mathrm{~m}$ de profundidade.

O padrão de drenagem observado entre os rios Gramame e Mucatu evidencia, também, um forte controle estrutural, onde o provável soerguimento do aqui denominado Alto Estrutural Coqueirinho (Figuras $4 \mathrm{a}$ e $4 \mathrm{~b}$ ) vem provocando um processo de dissecação acentuada, com vales extremamente encaixados e intenso recuo nas cabeceiras de drenagem atestado pelas declividades superiores a $47 \%$ e talvegues a mais de $100 \mathrm{~m}$ de desnível em relação aos topos dos tabuleiros. Como exemplos podem ser citadas as cabeceiras de drenagem dos riachos do Caboclo e do Pau-Ferro (Figuras 4b), afluentes da margem direita do rio Guruji.

A drenagem assimétrica é facilmente constatada nos afluentes dos rios Gramame e Guruji e Riacho Engenho Velho, este último localizado no extremo sul da área de estudo. Em todos esses rios os afluentes das respectivas margens à direita apresentam comprimento muito superior, com entalhamento fluvial acentuado e declividade das cabeceiras de drenagem evidenciando forte recuo (Figuras 4a e 4b).

As falésias mais altas de todo o litoral do Estado da Paraíba são encontradas na porção leste do Alto Estrutural Coqueirinho, com alturas superiores a 40 m (Figura 4b). Essas falésias esculpidas em sedimentos da Formação Barreiras atualmente não sofrem mais ação marinha, evidenciando um provável soerguimento. Atualmente, nessas falésias ocorrem exclusivamente processos erosivos ligados à dinâ- mica continental, como escoamento difuso e concentrado, solifluxão, deslizamentos, escorregamentos e corridas de lama (quando o fluxo é confinado dentro das voçorocas preexistentes). Essas falésias inativas possuem declividades elevadas, porém inferiores às verificadas nas falésias ativas. Em alguns casos, acham-se recobertas por vegetação, indicando estabilização por tempo suficientemente longo para o estabelecimento da mesma.

Outra provável evidência de continuidade do processo de soerguimento do Alto Estrutural Coqueirinho é a presença conspícua de afloramentos do Calcário Maria Farinha, ao longo das praias adjacentes a este compartimento de relevo, mas completamente ausente no resto do litoral paraibano.

Entre os vales dos rios Mucatu e Graú, as cotas altimétricas são bastante elevadas atingindo altitudes superiores a $100 \mathrm{~m}$, em média, e com declividades muitas vezes superiores a $47 \%$. O relevo apresenta-se bastante dissecado, com uma alta densidade da rede de drenagem, diferenciando-se praticamente de todas as outras superfícies da área de estudo (Figuras 4a e 4b). As formas predominantes são constituídas por "quase tabuleiros", às vezes, aproximando-se de formas colinosas pouco evoluídas. Esse modelado, segundo Kaizuca (1963; apud. Suguio, 1999) representaria a sequiência evolutiva de superfícies geomorfológicas, equivalente à fase intermediária entre as superfícies tabular e colinosa (Figura 5).

A depressão do Abiaí, localizada no extremo sul da área de estudo, constitui outro importante compartimento morfológico da região. Sua origem pode estar relacionada à intensa erosão dos arenitos da Formação Barreiras e dissolução dos calcários sotopostos. Esses processos foram acelerados por falhas e fraturas, que condicionam atualmente uma rede de drenagem constituída por vários rios e riachos que convergem para a depressão do Abiaí (Figuras 4a 4b). Provavelmente, essa intensa atividade mecânica, resultante da convergência da rede de drenagem local, provocou acelerada erosão nessa região. Outro fato que reforça esta interpretação é a existência de extensos afloramentos do Calcário Gramame nas vertentes voltadas para a depressão do Abiaí, que também ocorre em pequenos morrotes testemunhos e outras elevações no interior da mesma. Essas evidências sugerem uma origem denudacional da depressão e não por tectônica.

Araújo (1993), com base em critérios geomorfológico e estruturais, sugeriu também possível comunicação das águas da depressão do Abiaí com o mar, no passado, através do vale do riacho da Bueira (Figura 3a). Esse vale fluvial apresenta-se, atualmente, bastante assoreado e com dimensões incompatíveis com o volume de água drenado.

Para Araújo (op cit.), a desembocadura da bacia do Abiaí através do riacho da Bueira está relacionada a um momento anterior ao basculamento do tabuleiro, que suporta parte do sítio urbano de Pitimbu, Taquara e a bacia do riacho Engenho Velho (Figuras $4 \mathrm{a}$ e 4b). As evidências 


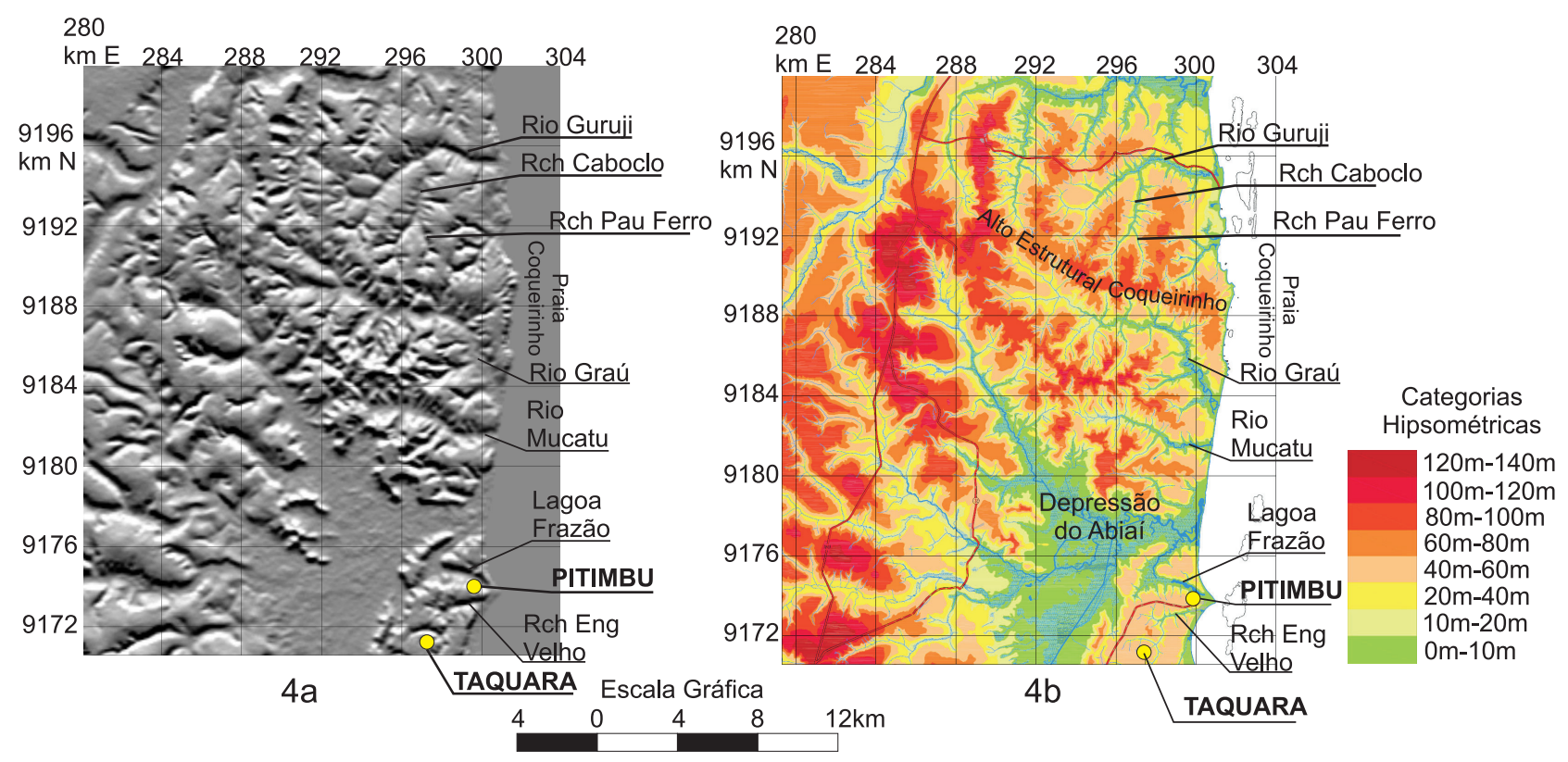

Figura 4. Imagem Shutle Radar Topographic Mission (SRTM) e carta hipsométrica de parte da Depressão do Abiaí.

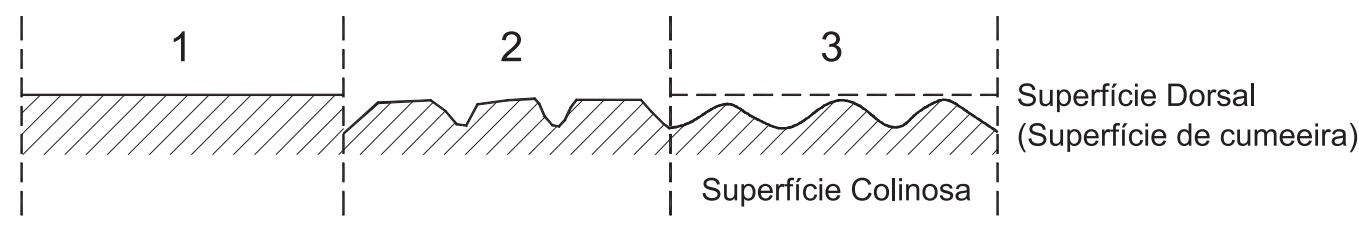

Figura 5. Seqüência evolutiva de superfície geomorfológica, segundo Kaizuca (1963; apud. Suguio, 1999). 1. Deposição sedimentar ou área arrasada por longos processos erosivos. 2. Soerguimento ou descida do nível de base erodindo a superfície e formando tabuleiros. 3. Continuidade dos processos erosivos em clima Tropical Úmido gerando superfície colinosa.

que ratificam esse basculamento, com soerguimento menos acentuado da porção norte-nordeste desse tabuleiro, estão presentes nas cotas topográficas, que decrescem de sudoeste para nordeste, respectivamente de 63 para $40 \mathrm{~m}$. Podem ser citadas também as diferentes profundidades do calcário Gramame, verificadas através de poços tubulares perfurados na área, que na porção sudoeste desse tabuleiro é quase aflorante em função da intensa dissecação na Formação Barreiras e, para o norte, nas proximidades da Cidade de Pitimbu, encontra-se a cerca de $30 \mathrm{~m}$ de profundidade. Outro aspecto que apóia esse provável basculamento é a mudança brusca na direção de fluxo do Riacho Engenho Velho, que do baixo até o médio curso possui direção leste-oeste, e a partir daí, passa brusca- mente para a direção norte-sul. Caso não tivesse ocorrido soerguimento mais acentuado na porção sul-sudoeste desse tabuleiro, provavelmente o riacho Engenho Velho desenvolver-se-ia segundo a mesma direção do baixo e médio curso, uma vez que a litologia à montante desse ponto é praticamente a mesma.

Esse mesmo tabuleiro, onde se localiza parte dos sítios urbanos de Pitimbu e Taquara, apresenta suas vertentes voltadas para a lagoa do Frazão mais entalhadas e com cursos d'água mais desenvolvidos que as vertentes do tabuleiro localizado ao norte dessa mesma lagoa. Essa característica corrobora também a idéia de um soerguimento diferenciado entre os tabuleiros localizados ao norte e ao sul da lagoa do Frazão (Figuras 4a e 4b). 


\section{CONCLUSÕES}

O domínio dos Baixos Planaltos Costeiros no Estado da Paraíba reflete as características estruturais da área relacionadas às reativações tectônicas cenozóicas. Sua configuração atual representa herança de uma complexa movimentação de blocos falhados que originam soerguimentos distintos e basculamentos, visualizados através das diferentes cotas altimétricas, da exumação de camadas sotopostas e dos diferentes níveis dos entalhes fluviais. $\mathrm{O}$ arcabouço estrutural também influenciou fortemente o padrão da rede de drenagem e conseqüentemente a disposição dos tabuleiros.

O compartimento setentrional, ao norte do vale do rio Gramame, apresenta tabuleiros com superfícies mais extensas e altitudes geralmente inferiores, contínuos e alinhados, predominantemente, na direção leste-oeste.

No litoral sul, que representa toda porção meridional do vale do rio Gramame, o relevo apresenta-se mais dissecado, com tabuleiros menos extensos e com cotas altimétricas superiores. Os entalhes fluviais são mais aprofundados e estes exumam as formações do Grupo Paraíba.

Provavelmente essas diferenças entre os dois compartimentos sejam respostas a movimentos tectônicos distintos em intensidade, orientação e cronologia dos esforços, visto que as características geomorfológicas são bastante diferenciadas entre os dois compartimentos sustentados pela mesma litologia, isto é, sedimentos areno-argilosos da Formação Barreiras.

\section{REFERÊNCIAS BIBLIOGRÁFICAS}

ALHEIROS, M. M.; LIMAFILHO, M. F.; FERREIRA, M. G. V. X. Formação Cabo em Recife: limite setentrional da bacia Sergipe-Alagoas. In: SIMPÓSIO DE GEOLOGIA DO NORDESTE, 13., 1989, Fortaleza; SIMPÓSIO NACIONAL DE ESTUDOS TECTÔNICOS, 2., 1989, Fortaleza. Boletim do Núcleo de Fortaleza da SBG, n. 11, p. 150-152.

ALHEIROS, M. M.; LIMA FILHO, M. F.; MONTEIRO, F. A. J.; OLIVEIRA FILHO, J. S. Sistemas deposicionais na Formação Barreiras no Nordeste Oriental. In: CONGRESSO BRASILEIRO DE GEOLOGIA, 35., 1988, Belém. Anais... Belém: SBG, 1988. v. 2, p. 753-760.

ALMEIDA, J. A. C. Calcários recifais eocênicos da Formação Maria Farinha na sub-bacia Alhandra, Paraíba: aspectos taxionômicos, paleoecológicos, paleoambientais e estratigráficos. 2000. 143 f. Dissertação (Mestrado) - Centro de Tecnologia, Universidade Federal do Pernambuco, Recife, 2000.

ARAI, M. A grande elevação eustática do Mioceno: a ver- dadeira origem do Grupo Barreiras. In: CONGRESSO DA ASSOCIAÇÃO BRASILEIRA DE ESTUDOS DO QUATERNÁRIO, 10., 2005. Guarapari. Anais...Guarapari: ABEQUA, 2005.

ARAI, M.; UESUGUI, N.; ROSSETTI, D. F.; GOES, A. M. Considerações sobre a idade do Grupo Barreiras no Nordeste do Pará. In: CONGRESSO BRASILEIRO DE GEOLOGIA, 35., 1988. Belém. Anais... Belém: SBG, 1988. p. 738-752.v. 2.

ARAÚJO, M. E. Estudo geomorfológico do extremo sul do litoral da Paraíba. 1993. Dissertação (Mestrado) Instituto de Geociências, Universidade Federal da Bahia, Salvador, 1993.

ASMUS, H. E. Controle estrutural da deposição mesozóica nas bacias da margem continental brasileira. Revista Brasileira de Geociências, São Paulo, v. 5, n. 3, p. 160-175, 1975.

BARBOSA, J. A. Evolução da Bacia Paraíba durante o Maastrichitiano-Paleoceno - formações Gramame e Maria Farinha, NE do Brasil. 2004. 219 f. Dissertação (Mestrado) Centro de Tecnologia e Geociências, Universidade Federal do Pernambuco, Recife, 2004.

BARBOSA, J. A.; SOUZA, E. M.; LIMA FILHO, M. F.; NEUMANN, V. H. A estratigrafia da Bacia Paraíba: uma reconsideração. Estudos Geológicos CTG/UFPE, Recife, v. 13, p. 89-108, 2004.

BARRETO, A. M. F.; BEZERRA, F. H. R.; SUGUIO, K.; TATUMI, S. H.; YEE, M.; PAIVA, R. P.; MUNITA, C. S. Late Pleistocene marine terrace deposits in northeastern Brazil: sea-level change and tectonic implications. Paleogeography, Paleoclimaology, Paleoecology, v. 179, p. 57-69, 2002.

BEZERRA, F. H. R.; VITA-FINZI, C. How active is a passive margin? Paleoseismicity in northeastern Brazil. Geology, Boulder, v. 28, p. 591-594, 2000.

BEZERRA, F. H. R.; LIMA FILHO, F. P.; AMARAL R. F.; CALDAS, L. H. O.; COSTA NETO, L. X. Holocene coastal tectonics in NE Brazil. In: STEWART, I. S.; VITA-FINZI, C. (Coord.). Coastal Tectonics. Geologic Society London, 1998. p. 279-293. v. 146. (Special Publication).

BEZERRA, F.H. R.;AMARO, R. F.; VITA-FINZI, C.; SAADI, A. Pliocene-Quaternary fault control of sedimentation and coastal plain morphology in NE Brazil. Journal of South American Earth Science, v. 14, n. 1, p. 61-75, 2001. 
BRASIL. Ministério de Minas e Energia. CPRM. Geologia e recursos minerais do Estado da Paraíba. Recife: CPRM, 2002. 142 p. il., 2 mapas. Escala 1:500.000.

BRITO NEVES, B. B.; RICCOMINI, C. FERNANDES, T. M. G.; SANT'ANNA, L. G. O sistema tafrogênico terciário do saliente oriental nordestino na Paraíba: um legado proterozóico. Revista Brasileira de Geociências, v. 34, n. 1, p. 127-134, 2004.

GOPINATH, T. R.; COSTA, C. R. S.; JÚNIOR, M. A. S. Minerais pesados e processos deposicionais dos sedimentos da Formação Barreiras, Paraíba. In: SIMPÓSIO DE GEOLOGIA DO NORDESTE, 15., 1993. Natal. Atas... Natal: SBG/Núcleo Nordeste, 1993.p. 47-48. v. 1.

LEALE SÁ, L. T. Levantamento geológico-geomorfológico da Bacia Pernambuco-Paraíba, no trecho compreendido entre Recife-PE e João Pessoa-PB. 1998. 127 f. Dissertação (Mestrado) - Centro de Tecnologia, Universidade Federal do Pernambuco, Recife, 1998.

LEITE, L. W. Geomorfologia dos tabuleiros costeiros de Sergipe. In: CONGRESSO BRASILEIRODEGEOLOGIA, 27. , 1973, Aracaju. Anais... Aracaju: SBG, 1973. p. 373-384, v. 1.

MABESOONE, J. M. Sedimentary basins of northeast Brazil. Recife: UFPE/CT/DG, 1994. 310 p. (Publicação Especial, 2).

MABESOONE, J. M.; ALHEIROS, M. M. Origem da bacia sedimentar costeira Pernambuco-Paraíba. Revista Brasileira de Geociências, v. 18, n. 4, p. 476-482, 1988.

MABESOONE, J. M.; ALHEIROS, M. M. Revisão geológica da faixa sedimentar costeira de Pernambuco, Paraíba e parte do Rio Grande do Norte - base estrutural. Estudos Geológicos UFPE, série B, Recife, v. 10, p. 33-44, 1991.

PONTE, F. C. Estudo morfoestrutural da Bacia SergipeAlagoas. Boletim Técnico da PETROBRAS, Rio de Janeiro, v. 12, n. 3, 1969.

RAND, H. M. Estudos geofísicos na faixa litorânea no sul do Recife. 1976. 101 f. Tese (Livre-Docência) - Departamento de Geologia, Universidade Federal do Pernambuco, Recife, 1976.

SUGUIO, K. Geologia do Quaternário e mudanças ambientais: $($ passado + presente $=$ futuro $)$. São Paulo: Paulo’s Comunicação e Artes Gráficas, 1999. 366 p. 